\title{
Motivating through Managing by Walking Around
}

\author{
Pablo Casas-Arce, Arizona State University,casas.arce@gmail.com \\ F. Asís Martínez-Jerez, University of Notre Dame, asismartinez@nd.edu \\ Joseph Moran, PwC, jdmoran17@gmail.com
}

April 25, 2019

In memory of Leo Cesario

\begin{abstract}
:
In this paper, we analyze the motivational effects of managing by walking around (MBWA), a management style that emphasizes managers' unstructured visits to the rank and file of the company. We do so by conducting a field experiment in the retail division of a medium-sized bank located in Latin America. We find that branches increase their sales productivity by a significant ten percent in the window following the management visit, an effect that persists for at least a month after the event. Contrary to our expectations, we do not find that the incentive effect of the visit is stronger for those branches located further away from the bank's headquarters.
\end{abstract}

Keywords: $M B W A$, Management by walking around, leadership, culture, teams, incentives, tournaments.

JEL Classification: D23; J53; M50

\footnotetext{
${ }^{*}$ We thank Bob Gibbons, Shelley Li, Lisa LaViers, Albert Saiz, Jee-Eun Shin, Robert Simons, Anita Tucker, and seminar participants at Cornell University, CPMRE Conference, EXRIMA, George Washington University, Harvard Business School, IAP-Cambridge Symposium, MAS Conference, and University of Minnesota for helpful comments. Casas-Arce gratefully acknowledges the financial support from Arizona State University and the Spanish Ministry of Science Innovation and Universities, grant ECO2017-89240-P (AEI/FEDER, UE), and Martínez-Jerez from the University of Notre Dame. The project received IRB approval (protocol number 14-07-1967). All errors are our own.
} 


\section{INTRODUCTION}

In this paper we analyze the motivational effects of managing by walking around (MBWA). MBWA, popularized by Peters and Waterman's (1982) "In Search of Excellence," refers to a management style that emphasizes managers' unstructured visits to the rank and file of the company. By leaving the corner office and talking to team members, working with them, or helping when needed, managers can boost motivation, build trust, contribute to problem solving, and communicate the values of the organization. This practice, whose first systematic application is attributed to Hewlett Packard, is frequently cited in management books and credited with contributing to the success of firms such as Disney, ServiceMaster and ING-Direct (Peters and Waterman, 1982; Heskett, Sasser, and Schlesinger, 1997).

Understanding whether and in what contexts MBWA is most effective is important in helping managers allocate their scarce time. Although the benefits of MBWA are much praised in the practitioners' literature, supported both by anecdotal evidence and by prescription (Peters and Austin, 1985; Heskett et al., 1997), the empirical evidence of the returns on this management activity is surprisingly scarce and inconclusive. Some studies even find that MBWA has negative effects on perceived performance (Tucker and Singer, 2015). We set out to address this problem by examining the extent to which a manager's personal interaction influences the incentives of the rank and file.

We designed a natural field experiment to test the impact of MBWA in collaboration with one of the retail divisions of a medium-sized bank located in Latin America. The division that we worked with has around 1,000 employees and 79 branches. The experiment allowed us to exogenously manipulate the schedule of field visits that the divisional manager made to the branches. To stress test the value of MBWA, we implemented our intervention at a time when 
incentives were strong, as the bank employees were engaged in a series of tournaments that the bank ran among its branches with the objective of stimulating sales. From June to November of 2015 , the bank organized every month three tournaments of about 26 branches each. At the end of the month, the top three branches in each tournament received a prize to be shared among all branch employees. Twice during this six month period branches were randomly assigned to one of three groups. Throughout the six months of the tournaments, we randomly planned the visits of the retail division manager to the branches. Each branch was visited once, and only once by the division manager.

We selected the timing of the visits in a manner that was orthogonal to branch productivity, with geography as the only limitation to randomization (branches were visited in clusters of proximity for convenience). Because we observe the performance of all branches before and after the randomize control trial, we can identify the causal impact of the implicit incentives derived from the manager's visits. We do this by comparing the daily performance of each branch in the dates neighboring the manager's visit against the performance to be expected absent any effect of the visit, thereby controlling for any time-invariant heterogeneity in the teams.

Our results show that MBWA is an important driver of employee motivation, as the manager's visit results in better team performance in subsequent periods for all of the bank branches. We find that branches increase their sales productivity by a significant ten percent in the ten-day window immediately following the manager's visit. Further, this effect seems to persist for at least a month after the management walk-around.

Contrary to our expectations, we do not find that the performance change is stronger or more persistent for branches that are more distant from the bank headquarters than for branches located closer to headquarters. 
Our paper makes a significant contribution to the literature in several respects. We contribute to the organizational economics literature by analyzing what managers do, focusing on one specific activity, the unstructured visits of top managers to the rank and file, and measuring its return in terms of increasing the motivation of the line employees. Top managers' time is an extremely scarce resource on which there are significant competing demands. How to allocate this time in the most beneficial way for the firm has been a constant concern of management science (Drucker, 1966). Mintzberg's (1973) seminal study called for the analysis of what activities constitute the work of a manager. However, the empirical research of what managers do has been rare, and mainly focused on styles or sets of actions and associated decisions (Bertrand and Schoar, 2003; Lazear, Shaw, and Stanton, 2015; Bandiera, Hansen, Prat, and Sadun, 2019).

To the best of our knowledge, this is the first paper to analyze the incentive effect of MBWA. Despite its popularity in management practice and in practitioners' literature (e.g. Peters and Waterman, 1982; Peters and Austin, 1985), the scholarly articles on MBWA are scarce. There is a stream of studies with a normative focus, often supported by anecdotal evidence, prescribing MBWA to build and communicate organizational values and employee commitment and motivation (Simons, 1995; Heskett et al., 1997). The existing empirical evidence is very limited, with the notable exception of the literature on safety rounds, or Gemba walks, in the healthcare field (see Singer and Tucker, 2014 for a comprehensive review). However, this literature consists mainly of case studies (e.g. Amsbary and Staples, 1991; Frankel, Gandhi and Bates, 2003) and some field research (e.g. Richardson, Watson, and Wong, 2007; Tucker and Singer, 2015) that focuses on the monitoring and problem identifying/solving dimension of MBWA. Further, the majority of these works are descriptive in their approach, while those with a quantitative approach usually measure the impact of safety walks through surveys asking employees (typically nurses) 
about their perceptions of safety climate, quality of the output, and value of the program (Frankel et al. 2008; Tucker and Singer 2015). ${ }^{2}$ We show that the unstructured visits to the field that constitute the essence of MBWA boost the motivation of the rank and file, resulting in a significant increase in sales.

The rest of the paper proceeds as follows. Section II describes our setting. We then develop a simple model in Section III to motivate the hypotheses that we test. Section IV describes the data and how we measure the empirical constructs, and Section V presents the empirical results. Finally, Section VI concludes. The detailed derivations of our theoretical results are described in the Appendix.

\section{INSTITUTIONAL SETTING}

For the purpose of this project, we partnered with a mid-sized bank in Latin America with over $\$ 2$ billion in assets. The bank has around 3,000 employees and 170 branches. There are two types of branches: those that target the general public (general branches) and those that target the retirees leveraging the bank's appointment as payment agent of the public pension system (service centers). Aside from the customer acquisition strategy and the portfolio of customers (service centers do not have SME clients), the work of both branch networks has many similarities in terms of commercial strategy, especially with respect to sales of financial products to existing customers. Our study focuses on the service center network.

In 2014, the bank decided to introduce a series of tournaments to motivate the branch employees to improve their performance. As the bank's CEO noted "we want to stimulate an urge to sell in our employees. The impulse of the tournament should lead the advisor in the branch to make that extra call to a customer with a high balance in checking account to acquire a term

\footnotetext{
2 The safety walks studies rarely look at objective outcome measures. One exception is Sexton et al. (2014), which looks at turnover although it does not find statistically significant results.
} 
deposit, or the teller to offer a debit card to the customer making a big withdrawal highlighting the safety and convenience of the plastic money." To increase the contest's salience, the retail bank director decided to brand it around the Soccer World Cup or Copa Mundial: "soccer is a religion here, so we want to leverage the vibe created by the World Cup and bring it to the daily work in the branches." We became actively involved in helping the bank's top management design the tournaments at this time.

The second edition of the tournament took place in 2015. In each of the six months between June and November 2015, the bank organized three independent tournaments in which roughly 26 service centers competed for multiple prizes. Aggregation of the performance in these 18 monthly tournaments served to identify a branch as the World Cup winner at the end of the six months. The general branch network simultaneously organized another tournament with very similar rules. Nevertheless, we focused our study in the service centers for two reasons. First, the divisional manager of this branch network had been recently appointed, therefore amplifying the potential signaling value of the visits. Second, the divisional manager of the service centers manifested his willingness to accommodate the randomized plan of unstructured visits to the branches.

In each of the three tournaments that took place every month, centers competed to score the maximum number of "goals." The center scored goals as a function of its level of excess performance over a series of commercial targets established in the variable compensation system. Generally speaking, the center scored a goal whenever the performance at the end of the month was between $100 \%$ and $110 \%$ of the target, two goals if it was between 110 and $130 \%$, three goals between 130 and $150 \%$, and four goals above $150 \%$. The goals were then aggregated for all the product dimensions to arrive at the final score that was used to rank the tournament participants. (Additional tie-breaking rules were also defined to allocate the prizes in case several branches 
obtained the same number of goals.)

In the monthly tournaments, each branch competed only against the other branches included in its group (referred to as a "zone," to echo the zones in the classificatory rounds of major international soccer tournaments like the World Cup). Twice in the six month period, we randomly allocated each branch to one of three groups of about 26 branches each. The randomization of branches aimed to minimize the presence of dynamic incentives (Casas-Arce and Martínez-Jerez, 2009). If groups remained the same for the six months, the participants could have inferred their relative strength from their performance in the previous tournaments, and their subsequent effort would likely have been affected by past performance. For instance, branches trailing consistently month after month might have lowered their effort, fearing they had no chance of winning in the future. Similar effects are observed, for instance, in RPE incentive plans when competition is considered unfair (Frederickson, 1992; Matsumura and Shin, 2006), and in budgeting when target levels are very difficult to achieve (Merchant and Manzoni, 1989; Fisher et al., 2003). By randomly allocating the branches to new groups, we minimize the influence of such dynamic effects.

A second dimension of our intervention was the planning of the branch visits. We randomized the chronological order of the visits within two restrictions. First, geographically close branches were to be visited in the same trip to minimize traveling time. Second, the division manager reserved a set of dates in his calendar to perform the visits. All 79 branches were visited once each in a total of 36 trips over the months of July to October. Notably, the randomization of the visits was orthogonal to the lotteries that assigned branches to groups in the tournament. Visits were announced to the branches with less than a week advance notice. Although there were slight variations from visit to visit, they typically spanned business and non-business hours. While the 
branch was open to the public, the divisional manager talked to the branch manager and walked the facilities observing the employees in action and sustaining short conversations with them. When the branch closed, it was the norm to have a town hall meeting in which the divisional manager engaged in a conversation with all the employees and emphasized the importance of the good work they were doing for the overall success of the bank.

The rules of each monthly tournament-i.e. the commercial targets-were announced at the beginning of each month, shortly after the official announcement of the winners of the prior month's tournaments. Branches could see their performance against targets, their standing in the tournament, and the goals that they and other branches had scored via daily updates on the bank's intranet.

\section{HYPOTHESES DEVELOPMENT}

\section{III.1 A Simple Model of MBWA and Incentives.}

In order to investigate the motivation effects of the branch visits, we develop a very stylized model of the signaling effects of MBWA (Spence, 1973). Consider a manager or leader $l$ that supervises a branch with (for simplicity) a single employee. Both the manager and employee are risk neutral. The value that the employee creates is given by $\pi(e, \theta)$, where $e$ is his effort choice at a cost of $c(e)=e^{2} / 2$ and $\theta$ is a parameter that captures the productivity of the employee. For simplicity, we assume a linear specification, where $\pi=\theta e$ and $\theta \in\{\underline{\theta}, \bar{\theta}\}$, with $0<\underline{\theta}<\bar{\theta}$. As such, $\pi$ and $\partial \pi / \partial e$ are both increasing in $\theta$. Hence, when $\theta$ increases, the employee becomes more productive and it is optimal to exert a higher effort. Note that the value $\pi$ could be sales, profits, or a multidimensional version of value that includes both financial as well as non-financial outcomes. 
Although we refer to $\theta$ as a productivity parameter, there are alternative interpretations of the model. In particular, $\theta$ can capture the importance that the manager attaches to the output of the employee, the amount of attention that the manager pays to the performance of the employee, the amount of monitoring that the manager is likely to exert, or the strength of career concerns in the organization, all of which may be (somewhat) unknown to the employee. On the other hand, the employee cares about it because his career advancement may depend on those factors, or simply because he derives higher utility if the manager is satisfied with his work. In this respect, MBWA may therefore serve as a signal about how much the manager cares about the output of the employee, or about the fact that the manager is paying attention to what the employee does.

The manager impacts the employee output through her leadership role. The manager can unleash the full productivity potential of the employee by inspiring him via a costly signaling action. Following Hermalin (1998), we let the manager move first, and the employee follows the leader after observing her action. We assume that $\theta$ is observable by the manager but is unknown to the employee. After observing $\theta$, the manager chooses action $a(\theta)$ at a $\operatorname{cost} K(a)$. We can think of $a$ as the way in which the manager aims to inspire the employee, and could be, for instance, a physical visit (MBWA), a phone call, or simply sending no message at all. For simplicity, suppose that $a \in\{0,1\}$, and let $K(0)=0$ and $K(1)=K$. Although the employee does not observe $\theta$, he can infer its realization (for example, how much the manager actually cares for his work) by observing the manager's action. After observing $a(\theta)$, the employee chooses his effort level $e$.

The employee receives a fixed salary $\alpha$ plus a share $\beta \in(0,1)$ of the value created. His utility is therefore $U=\alpha+\beta \pi(e, \theta)-c(e)$. Likewise, the manager's salary is linear in the employee's output, $w_{l}=\alpha_{l}+\beta_{l} \pi$. We can write the manager's utility as $U_{l}=\alpha_{l}+\beta_{l} \pi-K(a)$. 
To solve the model, we assume that all parties play a perfect Bayesian equilibrium and we rule out the use of weakly dominated strategies. ${ }^{3}$ We further assume that, in case of multiple equilibria, the manager can coordinate with the employee to play the most informative equilibrium, with the highest expected output. Let $\left(a^{*}, e^{*}\right)$ be the resulting equilibrium choices for the manager and the team, and $\pi^{*}$ the corresponding expected output. To evaluate the effects of the signaling action, we compare the expected value $\pi^{*}$ with the value $\underline{\pi}$ obtained when no signaling possibility by the manager exists and the employee exerts an average effort consistent with his priors of $\theta$, about how much the manager cares for his work. We denote the difference by $\Delta \pi^{*}=\pi^{*}-\underline{\pi}$.

The employee maximizes his expected utility given the information he has about $\theta$ from observing the action of the manager. His problem is therefore:

$$
\max _{e} E(\alpha+\beta \pi-c(e) \mid a(\theta))
$$

Anticipating the choice of the employee, the manager solves for the optimal ex-ante action:

$$
\max _{a} \alpha_{l}+\beta_{l} \pi-K(a) \text { s.t.e }=e^{*}(a)
$$

The manager would like to communicate the information about $\theta$ to the employee, as this helps increase expected output and improve efficiency by allocating high effort when it is most productive. However, the manager may be tempted to communicate that $\theta=\bar{\theta}$ even in the low state (when she does not care much about the value created by the employee) in order to induce a higher effort from the employee, as the manager does not suffer the cost of the higher effort. ${ }^{4}$ This divergence in preferences with the employee makes it difficult for the manager to sustain an informative equilibrium.

\footnotetext{
${ }^{3}$ Ruling out weakly dominated strategies eliminates some equilibria that are sustained by unrealistic beliefs. Several commonly used equilibrium refinements, such as trembling-hand perfection, preclude the use of such strategies.

${ }^{4}$ A simple example of when the manager would not care about the employee outcome is if the branch is in a nonstrategic location that is not a target of future growth for the bank.
} 
The following result shows that increasing the cost of the signaling action leads to higher profits as long as the cost is not too high:

PROPOSITION 1. Suppose that $K^{\prime \prime}>0$ is such that an informative equilibrium exists and let $K^{\prime \prime}>$ $K^{\prime}$. Then, $\Delta \pi^{*}\left(K^{\prime \prime}\right)>\Delta \pi^{*}\left(K^{\prime}\right)>0$.

When the cost of signaling $K$ is zero, the equilibrium involves pooling of both types, as the manager has every incentive to pretend that $\theta=\bar{\theta}$ when indeed $\theta=\underline{\theta}$, and the cost of doing so is nil. As a result, the manager cannot communicate any information in equilibrium. As the cost $K$ increases, the manager finds it less profitable to deviate when $\theta=\underline{\theta}$, making it possible for the manager to communicate some information. As a result, communication becomes more informative, and expected output increases. This is the case as long as $K$ is not too large. At some point, when the cost of the high action increases enough, the cost of signaling is so large that even with a $\theta=\bar{\theta}$ type, the manager would prefer to choose $a=0$ so the high type pools with the low type. At that point, the equilibrium is uninformative. If we characterize the cost of signaling $K$ as the time it takes the manager to travel to the branch, the message delivered by the manager would be uninformative for those branches located so close to headquarters that she could visit them without any effort, say on her way to or from work. As the distance to the headquarters increases, travel time and, therefore, the cost to the manager of visiting the branch increases. The higher cost makes the manager's presence more valuable to the employees, who correspondingly show an increasingly higher effort in response. Finally, if the branch is in a very remote location, with difficult communication, and it takes a very long time to reach the site, the costs of the trip may outweigh the potential benefits of the visit, and the manager may decide not to deliver the message. In that case, the absence of a visit becomes again uninformative to the employees, as the manager abstains from visiting them even when their productivity of effort is large. However, because in 
our setting the manager does decide to visit all the branches, we believe that the cost of signaling cannot be that large, and we restrict the results of our model to the parameter space in which we obtain an informative equilibrium (even if only partially informative).

\section{III.2 Hypotheses}

From the previous results, we can derive several hypotheses. First, to the extent that a manager's visit of a branch confers information about the importance of that branch's performance for the bank, we would expect an increase in output in the days following the visit. The first hypothesis describes the main effect of MBWA:

HYPOTHESIS 1. When a C-suite manager visits the rank and file, the team members of the front line location (the branch) increase their effort.

Besides this average treatment effect, Proposition 1 also predicts heterogeneous responses to the managers visit based on the cost of signaling. Because the cost of the manager from visiting a branch is higher for branches that are located further away from the bank's headquarters, we expect that the visit would be seen as a stronger message for those branches. As a result, we have the following hypothesis:

HYPOTHESIS 2. The incentive effect of the C-suite manager visits increases with the distance of the unit from headquarters.

Although the model is static, we can extrapolate that the increasing effect of MBWA with distance is likely to manifest both in terms of a stronger short-term response for branches that are 
farther from headquarters, but also with a response that lasts longer in time for those branches.

The next section describes the data we use to test these hypotheses.

\section{DATA}

To study the performance responses to MBWA we obtained sales information by branch from the market intelligence department of the bank. They extracted the data directly from the transactional systems of the bank. The retail division provided us with the census of branches.

In the definition of the dependent variable, we aimed to echo the behaviors that the bank's management wanted to promote. The performance metric of the tournament was the number of goals or points scored as a function of the product sales targets defined for each unit. However, as goals were scored in discrete intervals of sales relative to targets, their sensitivity to changes in effort was low, particularly at the daily level (most of the goals were scored in the second half of the month). To ensure that our dependent variable was sensitive to the sales effort of branches and employees over windows as short as a day, we decided to use underlying sales rather than goals as the dependent variable. As products typically have different ranges of sales, in constructing our sales performance variable we first normalize each product sales number by the population mean and standard deviation. Then, we weight sales by their scoring power, i.e., the number of goals that can be obtained by successfully selling the product.

In our empirical analyses we consider three types of event-time windows. First, we define the Event date as the month or the day of the divisional manager visit to the branch. Because the visit is announced a few days in advance (at most a week before according to the divisional manager), the Pre window identifies the month or the 5-business day period immediately preceding the event window. Finally, as we expect the incentive effect of MBWA to persist after 
the divisional manager visit takes place, we define the Post windows as a series of diverse length periods after the event.

To test whether the incentive effect of MBWA is a function of the remoteness of the branch, we search for the shortest driving distance between a branch and the bank headquarters using Google Maps (Dist).

Summary descriptive statistics for each of the variables can be found in Table 1 . Table 2 presents the schedule of management visits to the branches. The bulk of the visits happened between July and September with eight visits spanning to October 2015.

\section{RESULTS}

\section{V.1 The incentive effect of the manager visit.}

In this section, we analyze the changes in the sales productivity of branches around the time of the divisional manager visit. We do this by comparing the performance in the window of the visit against the performance expected if the visit had not happened. To build the expectation of performance, we use the average sales performance of the branch or employee and adjust it for time-specific circumstances such as day of the week, time trends, and whether the observation occurs during the time of the tournament.

We identify the average incentive effect of the manager visit by running the following regression:

$$
\text { Performance }_{i t}=\alpha_{i}+\beta_{1} \text { Tournament }_{t}+\beta_{2} \text { Pre }_{i t}+\beta_{2} \text { Event }_{i t}+\beta_{3} \text { Post }_{i t}+\gamma X_{t}+u_{i t},
$$

where $i$ denotes a branch; $t$ is the time period (month or day); $\alpha$ is a branch fixed-effect (representing human capital, demographics or market characteristics); Tournament is a dummy variable that takes a value of 1 in the months where the sales tournament is in effect and zero otherwise; Event, Pre, and Post are dummy variables that take the value of 1 if the observation 
occurs in the period (month or day) of the visit, the window immediately before, and the window immediately after the visit; and $X_{t}$ is a vector of variables capturing time effects, such as trends, or the impact of the day of the week or the week of the month.

We start the analysis by observing monthly performance because that is the time horizon of the branch incentives. Table 3 panel A presents the results for the monthly regressions. It shows a strong and significant bump in sales productivity in the month of the visit. The magnitude of the incentive effect is similar to that of the tournament. Further, the effect persists at a similar level for at least two months, and it only drops significantly for a three-month window (models (3) and (4)). Interestingly, there is no significant increase in sales in the month prior to the month of the visit, indicating that the increase in sales starts closer to the visit itself.

To understand better the causal link between the management visit and the sales, we graph the branches' abnormal sales volumes in 5-day event-time windows around the day of the visit. Figure 1 presents the coefficients of a regression model similar to [1] with twelve pre-visit window and twelve post-visit window dummies for the corresponding 5-day windows around the day of the visit. It is possible to appreciate that sales start being abnormally high the week before the visit, suggesting an immediate reaction to the announcement of the upcoming visit. Abnormal sales peak the day of the visit, and remain significantly high for up to a month and a half after the visit.

Table 3 Panel B presents the results for the daily data in a regression framework. Many of the same patterns as in Panel A arise here: there is a strong event-day effect of similar magnitude to the effect of the tournament, and persistence of the incentive effect for the following five to six weeks. There is also a significant and positive increase — although roughly half in size —in sales productivity in the days leading up to the divisional manager's visit, consistent with growing excitement in the branch in anticipation of the visit at a daily but not at a monthly level. 
In summary, the evidence presented in this section suggests a strong incentive effect of the divisional manager's unstructured branch visits. This effect results in an increase in the sales productivity of the branch and persists well beyond the day of the visit. Although there is a slight increase in sales in anticipation of the visit, the short length of the period and the small magnitude of the effect vis-à-vis the increase observed during and after the visit suggest that the physical presence of the divisional manager is what triggers the branches' additional commercial effort. Moreover, because the timing of the visit is exogenously determined well in advance of its occurrence, we can safely discard the possibility that the observed relationship is simply the effect of management choosing to visit the branches having the most success in the tournament at the time.

\section{$V .2$ The effect of branch distance to HQ on the heterogeneous responses to the manager's visit.}

In this section, we study whether and how the change in sales productivity displayed by the branches in response to the divisional manager's visit varies as a function of the driving distance between the branch and the headquarters that house the office of the divisional manager.

To analyze the impact of distance on the incentive effect of MBWA, we estimate regressions as follows:

$$
\begin{aligned}
& \text { Performance }_{i t}=\alpha_{i}+\beta_{1} \text { Tournament }_{t}+\beta_{2} \text { Pre }_{i t}+\beta_{3} \text { Event }_{i t}+\beta_{4} \text { Post }_{i t}+\beta_{5} \text { Event }_{i t} * \text { Dist }_{i} \\
& +\beta_{6} \text { Post }_{i t} * \text { Dist }_{i}+\gamma X_{t}+u_{i t},
\end{aligned}
$$

where Dist is the mean adjusted driving distance in kilometers between the branch and the bank headquarters and the remaining variables are defined as in [1]. Note that the variable Dist only appears in interactions with Event and Post. This is because the driving distance is time invariant for each branch and therefore it is subsumed in the branch fixed effect $\alpha_{i}$. The coefficients of 
interest in this section are $\beta_{5}$ and $\beta_{6}$, which measure the extent to which the performance improvement triggered by the manager's visit changes with the driving distance.

Table 4 Panel A shows the results for the monthly regressions. The rise in sales the month of the visit is comparable to that of Table 3, and it is similar for all branches regardless of their distance to headquarters as suggested by the coefficient on the interaction between the month of the visit and driving distance. The same patterns are observed for subsequent months. The generally insignificant coefficients on the interactions between driving distance and the windows post-visit fail to show that, as we predicted, the incentive effect of MBWA is larger or more persistent the more distant a branch is from headquarters.

Table 4 Panel B presents the results for the daily branch regressions. Here we can observe with more granularity the effect of driving distance on the persistence of the incentive effect of MBWA. Again, the coefficient on the interaction between the day of the visit and driving distance suggests that the incentive effect the day of the visit is similar for all branches. The generally insignificant coefficients of the interactions between driving distance and the post-visit windows suggest a similar persistence of the incentive effect for all branches regardless of their distance from headquarters.

In summary, the evidence presented in this section fails to show that the incentive effect of MBWA is larger or more persistent for employees who work further away from where top management is located.

\section{V.3 Robustness tests.}

Table 5 presents the results of placebo tests we conducted to assess the robustness of the results of our main empirical analyses. Our empirical analyses, as specified in Table 3, rely on the premise that any significant increase in sales around the time of the management visit is 
attributable to the motivational effect of the visit. While the randomization of the visits schedule gives us confidence on our identification strategy, we obtain further comfort in this section by falsifying the dates of the visit and comparing the patter of abnormal sales around the days of the visits and the falsified dates. Thus, we run the same econometric specifications as in column 4 of Table 3, but we define the event windows around the six months before, six months after, and twelve months after the action visit of the divisional manager to the branch.

The results of these placebo analyses are presented in Table 5. Although some of the coefficients are significant - notably that of the 10 to 30-day window in Panel A and the 1-month window in Panel B for the placebos 6-months before and 12-months after the visit-we do not observe the same consistent patterns as those exhibited in Table 3. Furthermore, the size of the coefficients in the placebo tests are generally considerably smaller than those derived from the actual treatment.

Thus, the evidence presented in this section reinforces the conclusion that the patterns of abnormal sales around the visit of the divisional manager are not spurious but caused by the motivational effects of the visit.

\section{CONCLUSION}

In this paper, we analyze the incentive effect of management by walking around (MBWA), a management style characterized by unstructured visits of top management to the rank and file. In collaboration with a medium-sized bank in Latin America, we conducted a field experiment in which we randomized the calendar of branch visits by the manager of a retail division of the bank. Each branch was visited once (and only once) by the divisional manager during a six-month-long sales stimulation program. We find that branches increase their sales productivity by a significant ten percent in the window following the management visit, an effect that persists for at least a 
month after the event. Contrary to our expectations, the incentive effect of the visit is not stronger nor more persistent for those branches located further away from the bank's headquarters, which houses the office of the divisional manager.

Our study shows the existence of a performance effect of unstructured management visits to the field, which is an important contribution given the lack of prior empirical evidence. Furthermore, the practical relevance of these findings is even more important at a time when competitive strategies seem to be focused on analytics and artificial intelligence, relegating the human component to a secondary role. Our evidence suggests that simply "managing by numbers" is unlikely to be enough to obtain optimal results, and points to the importance of personal interactions in the motivation of the workforce.

We interpret that the results that we find are caused by the motivational effect of employees feeling worthy of management attention. It is also plausible that branch employees may have felt that their work was monitored more closely after the visit; they may have realized that further career opportunities might be available for good performance than they previously thought; or the divisional manager may have imparted useful tips on how to improve performance. However, anecdotal evidence from pre and post RCT field interviews suggest that an important mechanism driving the increase in sales is the increased employee motivation stemming from their perception, induced by the visit, that top management cares about their work. In the words of the service center divisional manager, "the branch employees were really excited to hear that I was visiting their branch and spending time with them. Some of the branches even organized a party with decorations and snacks or a luncheon for my visit." Furthermore, the tone of the visits tended to be informal, and not focused on reviewing and assessing performance or working practices. Moreover, the short duration of the visits makes it unlikely for the divisional manager to significantly impart new skills 
that would drive a significant increase in sales, an explanation that cannot account for the fact that the increase in performance appears already in anticipation of the visit.

Nevertheless, we cannot completely rule out that the effect is caused by the learning of new best practices transmitted by the divisional manger or the elimination of dysfunctional behavior due to the perceived increase monitoring by headquarters. Because the precise mechanism driving our results cannot be scientifically contrasted, we preferred to leave our theoretical interpretation open and leave for future research the study of the effects of these different mechanisms. RCTs with different designs may help to shed light to this question. The manager may alternate visits during opening hours, more prone to increase the learning of the rank and file, with visits during non-commercial hours, better suited for an inspirational address. Also, the manager may deliver an inspirational message to some branches and a more hierarchical and compliance-oriented message to other branches. Another possible next step in the inquiry of this phenomenon is the development of a more complete contingency theory that would allow us to understand how the impact of MBWA is affected by different circumstances, such as the frequency of the manager visits, the hierarchical distance between the manger and the rank and file, the nature of the decentralized decisions, the culture of the firm, the manager's leadership style, or the characteristics of the field employees. Finally, this research could also be extended to address alternative managerial actions to understand the relative value of all the things that managers do and improve our understanding of how they drive firm performance. 


\section{REFERENCES}

Amsbary, J., and P. Staples. 1991. "Improving Administrator/Nurse Communication: A Case Study of 'Management by Wandering Around,"' Journal of Business Communication, 28(2): 101-112.

Bandiera, O., S. Hansen, A. Prat, and R. Sadun. 2019. "CEO Behavior and Firm Performance," Journal of Political Economy, forthcoming.

Bertrand, M. and A. Schoar. 2003. "Managing with style: The effects of managers on firm policies," The Quarterly Journal of Economics, 118(4): 1169-1208.

Casas-Arce, P. and A. Martínez-Jerez. 2009. "Relative Performance Compensation, Contests and Dynamic Incentives," Management Science, 55(8): 1306-1320.

Drucker, P. 1966. “The Effective Executive (2006 edition),” New York, NY: Harper Business.

Fisher, J., S. Peffer, and G. Sprinkle. 2003. "Budget-based Contracts, Budget Levels, and Group Performance," Journal of Management Accounting Research, 15: 51-74.

Frankel, A., T. Gandhi, and B. Gates. 2003. "Improving Patient Safety across a Large Integrated Health Care Delivery System," International Journal for Quality in Health Care, 15(1): 31-40.

Frankel, A., S. Grillo, M. Pitman, E. Thomas, L. Horowitz, M. Page, and B. Sexton. 2008. "Revealing and Resolving Patient Safety Defects: The Impact of Leadership WalkRounds on Frontline Caregiver Assessments of Patient Safety," Health Services Research, 43(6): 2050-2066.

Frederickson, J. R. 1992. "Relative Performance Information: The Effects of Common Uncertainty and Contract Type on Agent Effort," The Accounting Review, 67(4): 647-669.

Hermalin, B. 1998. "Toward an economic theory of leadership: Leading by example," The American Economic Review, 88(5): 1188-1206.

Heskett, J., E. Sasser, and L. Schlesinger. 1997. "The Service Profit Chain: How Leading Companies Link Profit and Growth to Loyalty, Satisfaction, and Value," New York, NY: The Free Press.

Lazear, E., K. Shaw, and C. Stanton. 2015. "The Value of Bosses," Journal of Labor Economics, 33(4): 823-861.

Matsumura, E. and J. Shin. 2006. "An Empirical Analysis of an Incentive Plan with Relative Performance Measures: Evidence from a Postal Service," The Accounting Review, 81: 533-566.

Merchant, K. and J.-F. Manzoni. 1989. "The Achievability of Budget Targets in Profit Centers: A Field Study," The Accounting Review, 64: 539-558. 
Mintzberg, H. 1973. “The Nature of Managerial Work (1980 edition)," Englewood Cliffs, NJ: PrenticeHall.

Peters, T. and N. Austin. 1985. "MBWA (Managing by Walking Around)," California Management Review, 28(1): 9-34.

Peters, T. and R. Waterman. 1982. "In Search of Excellence: Lessons from America's Best-Run Companies," New York, NY: Harper \& Row.

Richardson, S., S. Watson, and T. Wong. 2007. "Implementing Leadership Rounds to Improve Patient Safety," Healthcare Management Forum, 20(3): 38-41.

Sexton, B., P. Sharek, E. Thomas, J. Gould, C. Nisbet, A. Amspoker, M. Kowalkowski, R. Schwendimann, and J. Profit. 2014. "Exposure to Leadership WalkRounds in Neonatal Intensive Care Units is Associated with a Better Patient Safety Culture and Less Caregiver Burnout," BMJ Quality and Safety, 23(10): 814-822.

Simons, R. 1995. "Levers of Control: How Managers Use Innovative Control Systems to Drive Strategic Renewal," Cambridge, MA: Harvard Business School Press.

Singer, S and A. Tucker. 2014. "The Evolving Literature on Safety WalkRounds: Emerging Themes and Practical Messages," BMJ Quality and Safety, 23(10): 789-800 .

Spence, M. 1973. “Job Market Signaling,” The Quarterly Journal of Economics, 87(3): 355-374.

Tucker, A. and S. Singer. 2015. "The Effectiveness of Management-By-Walking-Around: A Randomized Field Study," Production and Operations Management, 24(2): 253-271. 


\section{APPENDIX: PROOFS}

This appendix provides the formal derivation of the result in Section III.

Proof of Proposition 1. Let $\mu$ denote the ex-ante probability of $\theta=\bar{\theta}$, and $E \theta$ the ex-ante expected productivity. After observing the leader's action $a(\theta)$, team members will form beliefs about $\theta$, where $\hat{\mu}(a)=\operatorname{Prob}(\theta=\bar{\theta} \mid a) \in[0,1], E(\theta \mid a)$ denotes the expectation of $\theta$ conditional on the observed action of the leader, which is increasing in $\hat{\mu}(a)$. In a perfect Bayesian equilibrium, such beliefs have to follow Bayes' rule. Moreover, from the employee's first-order condition, we have that $e_{i}^{*}(a)=\beta E(\theta \mid a)$. Denote $\bar{e}^{*}=\beta \bar{\theta}$ and $\underline{e}^{*}=\beta \underline{\theta}$ the optimal effort choices when the employee knows the state of the world is $\bar{\theta}$ and $\underline{\theta}$, respectively.

There are three types of equilibria: pooling, fully separating, and partially separating equilibria. A pooling equilibrium in which $a^{*}=0$ for all $\theta$ always exists in which the employee's expectations satisfy $E(\theta \mid a)=E \theta$ for all $a$. This equilibrium is completely uninformative for the employee. (Likewise, there may also exist a pooling equilibrium with $a^{*}=1$ for all $\theta$ in which the employee's expectations satisfy $E(\theta \mid 1)=E \theta$ and $E(\theta \mid 0)=\underline{\theta}$. However, we do not consider it because the manager prefers the pooling equilibrium with $a^{*}=0$, as it yields the same expected output without incurring the signaling cost.)

In all other equilibria, in which both $a=0$ and $a=1$ are played in equilibrium with positive probability, $E(\theta \mid a)$ (and hence $\left.e_{i}^{*}(a)\right)$ must be (weakly) increasing in $a$. Otherwise, if $E(\theta \mid a)$ were decreasing in $a$, the leader would prefer to set $a=0$ for all $\theta$, as doing so is less costly, and moreover convinces the team members that $E(\theta \mid a)$ is higher, encouraging them to exert higher effort and increase expected output.

In order to sustain such an informative equilibrium, the following incentive compatibility (IC) constraints for the manager must be satisfied: 


$$
\begin{aligned}
& \beta_{l} \pi\left(e^{*}(1), \bar{\theta}\right)-K \geq \beta_{l} \pi\left(e^{*}(0), \bar{\theta}\right) \\
& \beta_{l} \pi\left(e^{*}(0), \underline{\theta}\right) \geq \beta_{l} \pi\left(e^{*}(1), \underline{\theta}\right)-K .
\end{aligned}
$$

Notice that both these constraints cannot be binding at the same time because $\bar{\theta}>\underline{\theta}$. As a result, we cannot have indifference between $a=0$ and $a=1$ for both types at the same time. It follows that we can have either a fully separating equilibrium (FSE), in which $a^{*}(\underline{\theta})=0$ and $a^{*}(\bar{\theta})=1$, and two partially separating equilibria (denoted PSE1 and PSE2), in which one of the two types mixes between the two signals. In PSE $1, a^{*}(\underline{\theta})=1$ with probability $p, a^{*}(\underline{\theta})=0$ with probability $1-p$, and $a^{*}(\bar{\theta})=1$ with probability 1 . In PSE2, $a^{*}(\underline{\theta})=0$ with probability 1 , $a^{*}(\bar{\theta})=1$ with probability $q$, and $a^{*}(\bar{\theta})=0$ with probability $1-q$.

Consider FSE first. The equilibrium expected output is $\pi^{*}=\mu \pi\left(\bar{e}^{*}, \bar{\theta}\right)+(1-$ $\mu) \pi\left(\underline{e}^{*}, \underline{\theta}\right)$, and the manager's expected utility is $U_{L}^{*}=\beta_{L} \pi^{*}-\mu K$. This equilibrium exists for any $K \in\left[\beta_{l} \underline{\theta}\left(\bar{e}^{*}-\underline{e}^{*}\right), \beta_{l} \bar{\theta}\left(\bar{e}^{*}-\underline{e}^{*}\right)\right]$, as the IC constraint for $\bar{\theta}$ fails when $K>\beta_{l} \bar{\theta}\left(\bar{e}^{*}-\underline{e}^{*}\right)$, and the IC constraint for $\underline{\theta}$ fails when $K<\beta_{l} \underline{\theta}\left(\bar{e}^{*}-\underline{e}^{*}\right)$. Notice that $\pi^{*}$ is independent of $K$ under this equilibrium.

Consider now PSE1. Because the manager mixes when $\theta=\underline{\theta}$, he must be indifferent between the two actions: $\beta_{l} \pi\left(e^{*}(0), \underline{\theta}\right)=\beta_{l} \pi\left(e^{*}(1), \underline{\theta}\right)-K$. Bayesian updating also requires that $E(\theta \mid 0)=\underline{\theta}$, so $e^{*}(0)=\underline{e}^{*}$, and $e^{*}(1) \in\left[e^{*}(E \theta), \bar{e}^{*}\right]$. Therefore, this equilibrium exists for any $K \in\left[\beta_{l} \underline{\theta}\left(e^{*}(E \theta)-\underline{e}^{*}\right), \beta_{l} \underline{\theta}\left(\bar{e}^{*}-\underline{e}^{*}\right)\right]$, as we cannot satisfy the indifference condition outside of this range. Furthermore, at $K=\beta_{l} \underline{\theta}\left(\bar{e}^{*}-\underline{e}^{*}\right)$ we must have $E(\theta \mid 1)=\bar{\theta}$ and $e^{*}(1)=$ $\bar{e}^{*}$ (i.e. the fully separating equilibrium), while at $K=\beta_{l} \underline{\theta}\left(e^{*}(E \theta)-\underline{e}^{*}\right)$ we have $E(\theta \mid 1)=E \theta$ and $e^{*}(1)=e^{*}(E \theta)$ (i.e. the pooling equilibrium). The equilibrium expected output in this case is 


$$
\pi^{*}=\mu \pi\left(e^{*}(1), \bar{\theta}\right)+(1-\mu)\left[p \pi\left(e^{*}(1), \underline{\theta}\right)+(1-p) \pi\left(\underline{e}^{*}, \underline{\theta}\right)\right] .
$$

If we substitute for $e^{*}(1)$ from the indifference condition, it follows after some algebra that:

$$
\frac{\partial \pi^{*}}{\partial K}=\frac{1}{\beta_{l}}\left(\frac{E \theta}{\underline{\theta}}-1\right)>0
$$

Therefore, expected output is increasing in $K$. Moreover, the expected output under PSE1 lies between that of the pooling and the fully separating equilibria.

Finally, consider PSE2. Because the manager mixes when $\theta=\bar{\theta}$, he must be indifferent between the two actions: $\beta_{l} \pi\left(e^{*}(1), \bar{\theta}\right)-K=\beta_{l} \pi\left(e^{*}(0), \bar{\theta}\right)$. Bayesian updating also requires that $E(\theta \mid 1)=\bar{\theta}$, so $e^{*}(1)=\bar{e}^{*}$, and $e^{*}(0) \in\left[\underline{e}^{*}, e^{*}(E \theta)\right]$. Therefore, this equilibrium exists for any $K \in\left[\beta_{l} \bar{\theta}\left(\bar{e}^{*}-e^{*}(E \theta)\right), \beta_{l} \bar{\theta}\left(\bar{e}^{*}-\underline{e}^{*}\right)\right]$, as we cannot satisfy the indifference condition outside of this range. Furthermore, at $K=\beta_{l} \bar{\theta}\left(\bar{e}^{*}-\underline{e}^{*}\right)$ we must have $E(\theta \mid 0)=\underline{\theta}$ and $e^{*}(0)=$ $\underline{e}^{*}$ (i.e. the fully separating equilibrium), while at $K=\beta_{l} \bar{\theta}\left(\bar{e}^{*}-e^{*}(E \theta)\right)$ we have $E(\theta \mid 0)=E \theta$ and $e^{*}(0)=e^{*}(E \theta)$ (i.e. the pooling equilibrium). The equilibrium expected output in this case is

$$
\pi^{*}=\mu\left[q \pi\left(e^{*}(1), \bar{\theta}\right)+(1-q) \pi\left(e^{*}(0), \bar{\theta}\right)\right]+(1-\mu) \pi\left(e^{*}(0), \underline{\theta}\right) .
$$

If we substitute for $e^{*}(1)$ from the indifference condition, it follows after some algebra that:

$$
\frac{\partial \pi^{*}}{\partial K}=\frac{1}{\beta_{l}}\left(1-\frac{E \theta}{\bar{\theta}}\right)>0
$$

Therefore, expected output is also increasing in $K$. Furthermore, as with PSE1, the expected output under PSE2 lies between that of the pooling and the fully separating equilibria.

Because we select the most informative equilibrium, with the highest expected output, it follows that the equilibrium outcome must be pooling for $K \in[0, \underline{K}]$, PSE1 or PSE2 for $K \in$ $[\underline{K}, \bar{K}]$, FSE for $K \in[\bar{K}, \overline{\bar{K}}]$, and pooling for $K>\overline{\bar{K}}$. The proposition then follows from the fact 
that expected output $\pi^{*}$ for PSE1 and PSE2 is increasing in $K$ and between the expected output of pooling and FSE. Therefore, it is (weakly) increasing for all $K \leq \overline{\bar{K}}$. 
Figure 1. Abnormal Sales Performance Surrounding the Divisional Manager Visit

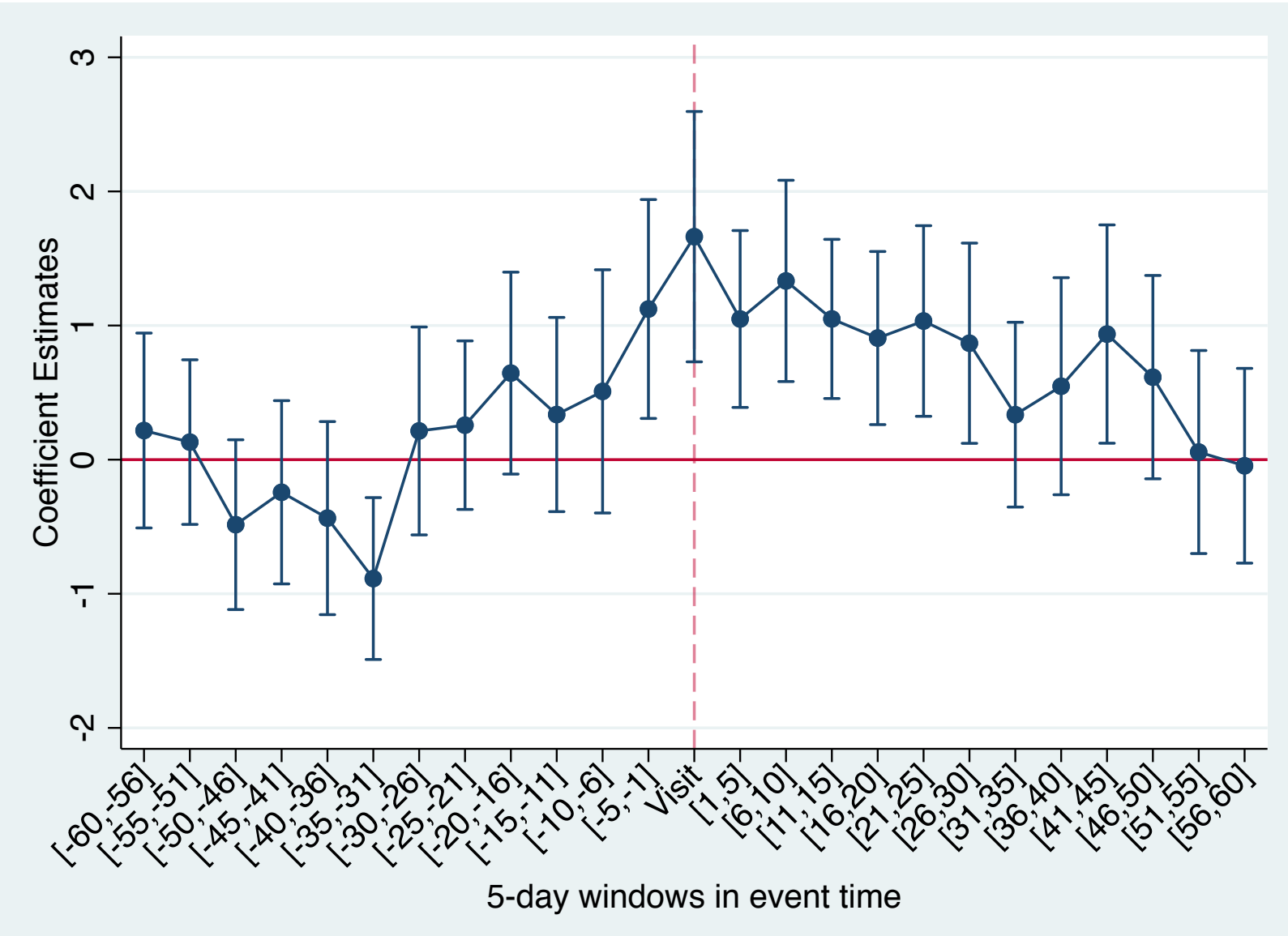




\section{TABLE 1. Summary statistics (79 unique branches)}

\begin{tabular}{lccccc}
\hline & Observations & mean & sd & min & max \\
\hline Weighted Normalized Performance (monthly) & 948 & $(0.00)$ & 8.27 & $(16.18)$ & 34.01 \\
Weighted Normalized Performance (daily) & 19,355 & $(0.00)$ & 7.94 & $(13.63)$ & 63.81 \\
Drive Distance & 79 & 289.4 & 385.1 & 2.8 & $1,254.0$ \\
\hline
\end{tabular}

Notes: This table reports the mean, standard deviation and main order statistics of the variables used in this study. Weighted

Normalized Performance is the sum of the individual product sales performed by a branch normalized by the population mean and standard deviation for each product and then multiplied by the number of goals scored if the branch meets the monthly sales target for that product; Drive Distance is the shortest driving distance between a branch and the bank headquarters calculated using Google Maps. 
Table 2. Frequency of Visits per month (June-November 2015)

\begin{tabular}{lc} 
& $\begin{array}{c}\text { Number of } \\
\text { Visits }\end{array}$ \\
\cline { 2 - 2 } July & 22 \\
August & 24 \\
September & 25 \\
October & 8 \\
\cline { 2 - 2 } TOTAL & 79 \\
\hline
\end{tabular}

Notes: This table reports the number of visits per month made by the Retail Division Manager of the Bank during the experiment period. The chronological order of the visits was randomly determined with two restrictions: (1) geographically close branches were to be visited in the same trip to minimize traveling time, and (2) the division manager reserved a set of dates in his calendar to perform the visits. 
Table 3 Panel A. Monthly Performance, Impact of the Visit

\begin{tabular}{|c|c|c|c|c|}
\hline VARIABLES & $\begin{array}{c}\text { Weighted } \\
\text { Normalized } \\
\text { Performance }\end{array}$ & $\begin{array}{c}\text { Weighted } \\
\text { Normalized } \\
\text { Performance }\end{array}$ & $\begin{array}{c}\text { Weighted } \\
\text { Normalized } \\
\text { Performance }\end{array}$ & $\begin{array}{c}\text { Weighted } \\
\text { Normalized } \\
\text { Performance }\end{array}$ \\
\hline Tournament & $\begin{array}{c}2.121^{* * *} \\
(0.294)\end{array}$ & $\begin{array}{c}1.902^{* * *} \\
(0.336)\end{array}$ & $\begin{array}{c}2.185^{* * *} \\
(0.362)\end{array}$ & $\begin{array}{c}1.892^{* * *} \\
(0.345)\end{array}$ \\
\hline 1-month Pre-visit Window & $\begin{array}{c}0.00569 \\
(0.386)\end{array}$ & $\begin{array}{c}0.332 \\
(0.394)\end{array}$ & $\begin{array}{c}0.129 \\
(0.418)\end{array}$ & $\begin{array}{c}0.269 \\
(0.418)\end{array}$ \\
\hline Month of the Visit & $\begin{array}{c}1.585^{* * *} \\
(0.440)\end{array}$ & $\begin{array}{c}1.942^{* * *} \\
(0.460)\end{array}$ & $\begin{array}{c}1.755^{* * *} \\
(0.491)\end{array}$ & $\begin{array}{c}1.861^{* * *} \\
(0.498)\end{array}$ \\
\hline 1-month Post-visit Window & $\begin{array}{c}1.361 * * * \\
(0.381)\end{array}$ & & & $\begin{array}{c}1.649 * * * \\
(0.524)\end{array}$ \\
\hline 2-month Post-visit Window & & $\begin{array}{c}1.508^{* * *} \\
(0.427)\end{array}$ & & \\
\hline 3-month Post-visit Window & & & $\begin{array}{c}0.870 \\
(0.532)\end{array}$ & \\
\hline Month 2 After Visit & & & & $\begin{array}{l}1.151^{*} \\
(0.671)\end{array}$ \\
\hline Month 3 After Visit & & & & $\begin{array}{c}-0.324 \\
(0.611)\end{array}$ \\
\hline Monthly linear time trend & $\begin{array}{c}-0.783^{* * *} \\
(0.066)\end{array}$ & $\begin{array}{c}-0.813^{* * *} \\
(0.069)\end{array}$ & $\begin{array}{c}-0.829 * * * \\
(0.076)\end{array}$ & $\begin{array}{c}-0.795^{* * *} \\
(0.076)\end{array}$ \\
\hline Service Center Fixed Effects & Yes & Yes & Yes & Yes \\
\hline Observations & 948 & 948 & 948 & 948 \\
\hline R-squared & 0.842 & 0.844 & 0.842 & 0.844 \\
\hline
\end{tabular}

Notes: This table reports OLS regressions of the branch monthly sales performance during the year when the RCT took place. The dependent variable, Weighted Normalized Performance, is the sum of the individual product sales performed by a branch normalized by the population mean and standard deviation for each product and then multiplied by the number of goals scored if the branch meets the monthly sales target for that product; Tournament is a dummy variable that takes the value of 1 if the sales tournament is running during the month of the observation and 0 otherwise; 1-month Pre-visit Window, Month of the Visit, 1-month Post-visit Window, and Month 2(3) After Visit are dummy variables that take the value of 1 if the observation occurs the month prior to, the month of, or the first, second, or third month after the visit of the division manager to the branch and 0 otherwise; 2(3)-month Post-visit Window are dummy variables that take the value of 1 if the observation occurs the 2 - or 3-month period after the visit of the division manager to the branch and 0 otherwise.

Clustered standard errors (branch level) in parentheses

$* * * \mathrm{p}<0.01, * * \mathrm{p}<0.05, * \mathrm{p}<0.1$ 
Table 3 Panel B. Daily Performance, Impact of the Visit

\begin{tabular}{|c|c|c|c|c|}
\hline VARIABLES & $\begin{array}{c}\text { Weighted } \\
\text { Normalized } \\
\text { Performance }\end{array}$ & $\begin{array}{c}\text { Weighted } \\
\text { Normalized } \\
\text { Performance }\end{array}$ & $\begin{array}{c}\text { Weighted } \\
\text { Normalized } \\
\text { Performance }\end{array}$ & $\begin{array}{c}\text { Weighted } \\
\text { Normalized } \\
\text { Performance } \\
\end{array}$ \\
\hline Tournament & $\begin{array}{c}1.273 * * * \\
(0.164)\end{array}$ & $\begin{array}{c}1.228 * * * \\
(0.164)\end{array}$ & $\begin{array}{c}1.109 * * * \\
(0.174)\end{array}$ & $\begin{array}{c}1.106 * * * \\
(0.173)\end{array}$ \\
\hline 5-day Pre-visit Window & $\begin{array}{c}0.793 * * \\
(0.361)\end{array}$ & $\begin{array}{c}0.836 * * \\
(0.363)\end{array}$ & $\begin{array}{c}0.979 * * * \\
(0.364)\end{array}$ & $\begin{array}{c}0.979 * * * \\
(0.364)\end{array}$ \\
\hline Day of the Visit & $\begin{array}{c}1.327^{* * *} \\
(0.420)\end{array}$ & $\begin{array}{c}1.371^{* * *} \\
(0.423)\end{array}$ & $\begin{array}{c}1.514^{* * *} \\
(0.428)\end{array}$ & $\begin{array}{c}1.514^{* * *} \\
(0.428)\end{array}$ \\
\hline 5-day Post-visit Window & $\begin{array}{c}0.709 * * \\
(0.270)\end{array}$ & & & $\begin{array}{c}0.897 * * * \\
(0.294)\end{array}$ \\
\hline 10-day Post-visit Window & & $\begin{array}{c}0.894 * * * \\
(0.244)\end{array}$ & & \\
\hline 30-day Post-visit Window & & & $\begin{array}{c}0.881 * * * \\
(0.197)\end{array}$ & \\
\hline Days 6 to 10 Post-visit & & & & $\begin{array}{c}1.180 * * * \\
(0.318)\end{array}$ \\
\hline Days 11 to 30 Post-visit & & & & $\begin{array}{c}0.802^{* * *} \\
(0.194)\end{array}$ \\
\hline Monthly linear time trend & $\begin{array}{c}-0.594 * * * \\
(0.045)\end{array}$ & $\begin{array}{c}-0.594 * * * \\
(0.045)\end{array}$ & $\begin{array}{c}-0.600 * * * \\
(0.046)\end{array}$ & $\begin{array}{c}-0.600 * * * \\
(0.046)\end{array}$ \\
\hline \multicolumn{5}{|l|}{ Fixed Effects: } \\
\hline Service Center & Yes & Yes & Yes & Yes \\
\hline Week of the Month & Yes & Yes & Yes & Yes \\
\hline Day of the Week & Yes & Yes & Yes & Yes \\
\hline Observations & 19,355 & 19,355 & 19,355 & 19,355 \\
\hline R-squared & 0.623 & 0.623 & 0.624 & 0.624 \\
\hline \multicolumn{5}{|c|}{$\begin{array}{l}\text { Notes: This table reports OLS regressions of the branch daily sales performance during the year when the RCT took place. The dependent } \\
\text { variable, Weighted Normalized Performance, is the sum of the individual product daily sales performed by a branch normalized by the } \\
\text { population mean and standard deviation for each product and then multiplied by the number of goals scored if the branch meets the monthly } \\
\text { sales target for that product; Tournament is a dummy variable that takes the value of } 1 \text { if the sales tournament is running during the day of } \\
\text { the observation and } 0 \text { otherwise; Day of the Visit, 5-day Pre-visit Window, 5(10)(30)-day Post-visit Window, and Days } 6(11) \text { to } 10(30) \text { Post- } \\
\text { visit are dummy variables that take the value of } 1 \text { if the observation occurs the day of, or in the periods defined as a function of the day of } \\
\text { the visit of the division manager to the branch and } 0 \text { otherwise. }\end{array}$} \\
\hline \multicolumn{5}{|c|}{ Clustered standard errors (by branch) in parentheses } \\
\hline$* * * \mathrm{p}<0.01, * * \mathrm{p}<0.05, * \mathrm{p}<0.1$ & & & & \\
\hline
\end{tabular}


Table 4 Panel A. Monthly Performance, Impact of the Visit and Distance Effect

\begin{tabular}{|c|c|c|c|c|}
\hline VARIABLES & $\begin{array}{c}\text { Weighted } \\
\text { Normalized } \\
\text { Performance }\end{array}$ & $\begin{array}{c}\text { Weighted } \\
\text { Normalized } \\
\text { Performance }\end{array}$ & $\begin{array}{c}\text { Weighted } \\
\text { Normalized } \\
\text { Performance }\end{array}$ & $\begin{array}{c}\text { Weighted } \\
\text { Normalized } \\
\text { Performance }\end{array}$ \\
\hline Tournament & $\begin{array}{c}2.122 * * * \\
(0.294)\end{array}$ & $\begin{array}{c}1.899 * * * \\
(0.338)\end{array}$ & $\begin{array}{c}2.187^{* * *} \\
(0.359)\end{array}$ & $\begin{array}{c}1.964 * * * \\
(0.332)\end{array}$ \\
\hline 1-month Pre-visit Window & $\begin{array}{c}0.005 \\
(0.386)\end{array}$ & $\begin{array}{c}0.333 \\
(0.395)\end{array}$ & $\begin{array}{c}0.129 \\
(0.412)\end{array}$ & $\begin{array}{c}0.223 \\
(0.405)\end{array}$ \\
\hline Month of the Visit & $\begin{array}{c}1.585 * * * \\
(0.436)\end{array}$ & $\begin{array}{c}1.942^{* * *} \\
(0.461)\end{array}$ & $\begin{array}{c}1.756 * * * \\
(0.491)\end{array}$ & $\begin{array}{c}1.818^{* * *} \\
(0.491)\end{array}$ \\
\hline $\begin{array}{l}\text { Drive Distance* } \\
\text { Month of the Visit }\end{array}$ & $\begin{array}{l}-0.001 \\
(0.001)\end{array}$ & $\begin{array}{l}-0.001 \\
(0.001)\end{array}$ & $\begin{array}{l}-0.001^{*} \\
(0.001)\end{array}$ & $\begin{array}{l}-0.001 \\
(0.001)\end{array}$ \\
\hline 1-month Post-visit Window & $\begin{array}{c}1.362 * * * \\
(0.381)\end{array}$ & & & $\begin{array}{c}1.610 * * * \\
(0.513)\end{array}$ \\
\hline $\begin{array}{l}\text { Drive Distance* } \\
\text { 1-month Post-visit Window }\end{array}$ & $\begin{array}{c}0.000 \\
(0.001)\end{array}$ & & & $\begin{array}{c}0.000 \\
(0.001)\end{array}$ \\
\hline 2-month Post-visit Window & & $\begin{array}{c}1.508 * * * \\
(0.421)\end{array}$ & & \\
\hline $\begin{array}{l}\text { Drive Distance* } \\
\text { 2-month Post-visit Window }\end{array}$ & & $\begin{array}{c}0.001 \\
(0.001)\end{array}$ & & \\
\hline 3-month Post-visit Window & & & $\begin{array}{c}0.873 \\
(0.531)\end{array}$ & \\
\hline $\begin{array}{l}\text { Drive Distance* } \\
\text { 3-month Post-visit Window }\end{array}$ & & & $\begin{array}{c}0.000 \\
(0.001)\end{array}$ & \\
\hline Month 2 After Visit & & & & $\begin{array}{l}1.123^{*} \\
(0.654)\end{array}$ \\
\hline $\begin{array}{l}\text { Drive Distance* } \\
\text { Month } 2 \text { After Visit }\end{array}$ & & & & $\begin{array}{c}0.001 \\
(0.001)\end{array}$ \\
\hline Month 3 After Visit & & & & $\begin{array}{l}-0.327 \\
(0.614)\end{array}$ \\
\hline $\begin{array}{l}\text { Drive Distance* } \\
\text { Month } 3 \text { After Visit }\end{array}$ & & & & $\begin{array}{l}-0.001 \\
(0.002)\end{array}$ \\
\hline Monthly linear time trend & $\begin{array}{c}-0.783^{* * *} \\
(0.066)\end{array}$ & $\begin{array}{c}-0.813^{* * *} \\
(0.069)\end{array}$ & $\begin{array}{c}-0.830 * * * \\
(0.076)\end{array}$ & $\begin{array}{c}-0.799 * * * \\
(0.076)\end{array}$ \\
\hline Service Center Fixed Effects & Yes & Yes & Yes & Yes \\
\hline Observations & 948 & 948 & 948 & 948 \\
\hline R-squared & 0.843 & 0.844 & 0.842 & 0.845 \\
\hline
\end{tabular}

Notes: This table reports OLS regressions of the branch monthly sales performance during the year when the RCT took place and analyzes whether the impact of the visit is contingent on the distance of the branch from the bank headquarters. The dependent variable, Weighted Normalized Performance, is the sum of the individual product sales performed by a branch normalized by the population mean and standard deviation for each product and then multiplied by the number of goals scored if the branch meets the monthly sales target for that product; Tournament is a dummy variable that takes the value of 1 if the sales tournament is running during the month of the observation and 0 otherwise; 1-month Pre-visit Window, Month of the Visit, 1-month Post-visit Window, and Month 2(3) After Visit are dummy variables that take the value of 1 if the observation occurs the month prior to, the month of, or the first, second, or third month after the visit of the division manager to the branch and 0 otherwise; 2(3)-month Post-visit Window are dummy variables that take the value of 1 if the observation occurs the 2- or 3-month period after the visit of the division manager to the branch and 0 otherwise. Drive Distance is the mean adjusted shortest driving distance between a branch and the bank headquarters calculated using Google Maps. "*” denotes interaction between two variables. Clustered standard errors (by branch) in parentheses

$* * * \mathrm{p}<0.01, * * \mathrm{p}<0.05, * \mathrm{p}<0.1$ 
Table 4 Panel B. Daily Performance, Impact of the Visit and Distance Effect

\begin{tabular}{|c|c|c|c|c|}
\hline VARIABLES & $\begin{array}{c}\text { Weighted } \\
\text { Normalized } \\
\text { Performance }\end{array}$ & $\begin{array}{c}\text { Weighted } \\
\text { Normalized } \\
\text { Performance }\end{array}$ & $\begin{array}{c}\text { Weighted } \\
\text { Normalized } \\
\text { Performance }\end{array}$ & $\begin{array}{c}\text { Weighted } \\
\text { Normalized } \\
\text { Performance }\end{array}$ \\
\hline Tournament & $\begin{array}{c}1.273^{* * *} \\
(0.164)\end{array}$ & $\begin{array}{c}1.229 * * * \\
(0.164)\end{array}$ & $\begin{array}{c}1.109 * * * \\
(0.174)\end{array}$ & $\begin{array}{c}1.107^{* * *} \\
(0.174)\end{array}$ \\
\hline 5-day Pre-visit Window & $\begin{array}{c}0.792^{* *} \\
(0.361)\end{array}$ & $\begin{array}{c}0.836 * * \\
(0.363)\end{array}$ & $\begin{array}{c}0.979 * * * \\
(0.364)\end{array}$ & $\begin{array}{c}0.979 * * * \\
(0.364)\end{array}$ \\
\hline Day of the Visit & $\begin{array}{c}1.327^{* * *} \\
(0.419)\end{array}$ & $\begin{array}{c}1.370^{* * *} \\
(0.422)\end{array}$ & $\begin{array}{c}1.514^{* * *} \\
(0.428)\end{array}$ & $\begin{array}{c}1.514^{* * *} \\
(0.428)\end{array}$ \\
\hline $\begin{array}{l}\text { Drive Distance* } \\
\text { Day of the Visit }\end{array}$ & $\begin{array}{l}-0.001 \\
(0.001)\end{array}$ & $\begin{array}{l}-0.001 \\
(0.001)\end{array}$ & $\begin{array}{l}-0.001 \\
(0.001)\end{array}$ & $\begin{array}{l}-0.001 \\
(0.001)\end{array}$ \\
\hline 5-day Post-visit Window & $\begin{array}{c}0.708^{* *} \\
(0.271)\end{array}$ & & & $\begin{array}{c}0.897 * * * \\
(0.295)\end{array}$ \\
\hline $\begin{array}{l}\text { Drive Distance* } \\
\text { 5-day Post-visit Window }\end{array}$ & $\begin{array}{l}-0.000 \\
(0.001)\end{array}$ & & & $\begin{array}{l}-0.000 \\
(0.001)\end{array}$ \\
\hline 10-day Post-visit Window & & $\begin{array}{c}0.894^{* * *} \\
(0.245)\end{array}$ & & \\
\hline $\begin{array}{l}\text { Drive Distance* } \\
\text { 10-day Post-visit Window }\end{array}$ & & $\begin{array}{l}-0.000 \\
(0.001)\end{array}$ & & \\
\hline 30-day Post-visit Window & & & $\begin{array}{c}0.881^{* * *} \\
(0.199)\end{array}$ & \\
\hline $\begin{array}{l}\text { Drive Distance* } \\
\text { 30-day Post-visit Window }\end{array}$ & & & $\begin{array}{l}-0.000 \\
(0.000)\end{array}$ & \\
\hline Days 6 to 10 Post-visit & & & & $\begin{array}{c}1.181^{* * *} \\
(0.319)\end{array}$ \\
\hline $\begin{array}{l}\text { Drive Distance* } \\
\text { Days } 6 \text { to } 10 \text { Post-visit }\end{array}$ & & & & $\begin{array}{l}-0.000 \\
(0.001)\end{array}$ \\
\hline Days 11 to 30 Post-visit & & & & $\begin{array}{c}0.802 * * * \\
(0.194)\end{array}$ \\
\hline $\begin{array}{l}\text { Drive Distance* } \\
\text { Days } 11 \text { to } 30 \text { Post-visit }\end{array}$ & & & & $\begin{array}{r}-0.000 \\
(0.00)\end{array}$ \\
\hline Monthly linear time trend & $\begin{array}{c}-0.594 * * * \\
(0.045)\end{array}$ & $\begin{array}{c}-0.594 * * * \\
(0.045)\end{array}$ & $\begin{array}{c}-0.601 * * * \\
(0.046)\end{array}$ & $\begin{array}{c}-0.600^{* * *} \\
(0.046)\end{array}$ \\
\hline Fixed Effects: & & & & \\
\hline $\begin{array}{l}\text { Service Center } \\
\text { Week of the Month }\end{array}$ & $\begin{array}{l}\text { Yes } \\
\text { Yes }\end{array}$ & $\begin{array}{l}\text { Yes } \\
\text { Yes }\end{array}$ & $\begin{array}{l}\text { Yes } \\
\text { Yes }\end{array}$ & $\begin{array}{l}\text { Yes } \\
\text { Yes }\end{array}$ \\
\hline Day of the Week & Yes & Yes & Yes & Yes \\
\hline Observations & 19,355 & 19,355 & 19,355 & 19,355 \\
\hline R-squared & 0.623 & 0.623 & 0.624 & 0.624 \\
\hline
\end{tabular}

Notes: This table reports OLS regressions of the branch daily sales performance during the year when the RCT took place and analyzes whether the impact of the visit is contingent on the distance of the branch from the bank headquarters. The dependent variable, Weighted Normalized Performance, is the sum of the individual product daily sales performed by a branch normalized by the population mean and standard deviation for each product and then multiplied by the number of goals scored if the branch meets the monthly sales target for that product; Tournament is a dummy variable that takes the value of 1 if the sales tournament is running during the day of the observation and 0 otherwise; Day of the Visit, 5-day Pre-visit Window, 5(10)(30)-day Post-visit Window, and Days 6(11) to 10(30) Post-visit are dummy variables that take the value of 1 if the observation occurs the day of, or in the periods defined as a function of the day of the visit of the division manager to the branch and 0 otherwise. Drive Distance is the mean adjusted shortest driving distance between a branch and the bank headquarters calculated using Google Maps. "*” denotes interaction between two variables.

Clustered standard errors (by branch) in parentheses

$* * * \mathrm{p}<0.01, * * \mathrm{p}<0.05, * \mathrm{p}<0.1$ 
Table 5 Panel A. Placebo Analysis. Monthly Performance, Impact of the Visit

\begin{tabular}{|c|c|c|c|}
\hline PLACEBO TIME & $\begin{array}{c}6 \text { months before } \\
\text { the visit }\end{array}$ & $\begin{array}{c}6 \text { months after } \\
\text { the visit }\end{array}$ & $\begin{array}{l}12 \text { months after } \\
\text { the visit }\end{array}$ \\
\hline VARIABLES & $\begin{array}{c}\text { Weighted } \\
\text { Normalized } \\
\text { Performance } \\
\end{array}$ & $\begin{array}{c}\text { Weighted } \\
\text { Normalized } \\
\text { Performance }\end{array}$ & $\begin{array}{c}\text { Weighted } \\
\text { Normalized } \\
\text { Performance }\end{array}$ \\
\hline Tournament & $\begin{array}{c}-2.884^{* * *} \\
(0.662)\end{array}$ & $\begin{array}{c}-1.289 * * * \\
(0.251)\end{array}$ & $\begin{array}{c}1.149 * * * \\
(0.183)\end{array}$ \\
\hline 1-month Pre-visit Window & $\begin{array}{c}0.357 \\
(0.506)\end{array}$ & $\begin{array}{c}0.478 \\
(0.307)\end{array}$ & $\begin{array}{l}-0.277 \\
(0.289)\end{array}$ \\
\hline Month of the Visit & $\begin{array}{c}0.917 \\
(0.715)\end{array}$ & $\begin{array}{c}0.504 \\
(0.310)\end{array}$ & $\begin{array}{l}-0.266 \\
(0.295)\end{array}$ \\
\hline Month 1 After Visit & $\begin{array}{l}1.367 * \\
(0.757)\end{array}$ & $\begin{array}{c}0.551 \\
(0.332)\end{array}$ & $\begin{array}{c}0.704 * * * \\
(0.263)\end{array}$ \\
\hline Month 2 After Visit & $\begin{array}{c}0.920 \\
(0.728)\end{array}$ & $\begin{array}{l}0.459 * \\
(0.270)\end{array}$ & $\begin{array}{c}0.367 \\
(0.245)\end{array}$ \\
\hline Month 3 After Visit & $\begin{array}{c}0.465 \\
(0.511)\end{array}$ & $\begin{array}{c}0.350 \\
(0.265)\end{array}$ & $\begin{array}{l}-0.0444 \\
(0.221)\end{array}$ \\
\hline Monthly linear time trend & $\begin{array}{c}-0.827 * * * \\
(0.081)\end{array}$ & $\begin{array}{c}-0.200 * * * \\
(0.042)\end{array}$ & $\begin{array}{c}-0.205^{* * *} \\
(0.031)\end{array}$ \\
\hline Service Center Fixed Effects & Yes & Yes & Yes \\
\hline Observations & 948 & 948 & 948 \\
\hline R-squared & 0.829 & 0.856 & 0.865 \\
\hline \multicolumn{4}{|c|}{$\begin{array}{l}\text { Notes: This table reports OLS regressions of the branch monthly sales performance during the year of the placebo } \\
\text { RCT period. The placebo periods are defined in event time where the event period occurs } 6 \text { months prior, } 6 \\
\text { months after, and } 12 \text { months after the month of the actual visit of the division manager to the branch. The } \\
\text { dependent variable, Weighted Normalized Performance, is the sum of the individual product sales performed by a } \\
\text { branch normalized by the population mean and standard deviation for each product and then multiplied by the } \\
\text { number of goals scored if the branch meets the monthly sales target for that product; Tournament is a dummy } \\
\text { variable that takes the value of } 1 \text { if the event time of the observation relative to the placebo visit coincides with } \\
\text { the event time of the sales tournament relative to the actual visit and } 0 \text { otherwise; } 1 \text {-month Pre-visit Window, } \\
\text { Month of the Visit, 1-month Post-visit Window, and Month 2(3) After Visit are dummy variables that take the } \\
\text { value of } 1 \text { if the observation occurs the month prior to, the month of, or the first, second, or third month after the } \\
\text { placebo visit of the division manager to the branch and } 0 \text { otherwise; 2(3)-month Post-visit Window are dummy } \\
\text { variables that take the value of } 1 \text { if the observation occurs the 2- or 3-month period after the placebo visit of the } \\
\text { division manager to the branch and } 0 \text { otherwise. }\end{array}$} \\
\hline \multicolumn{4}{|c|}{ Clustered standard errors (by branch) in parentheses } \\
\hline$* * * \mathrm{p}<0.01, * * \mathrm{p}<0.05, * \mathrm{p}<0.1$ & & & \\
\hline
\end{tabular}


Table 5 Panel B. Placebo Analysis. Daily Performance, Impact of the Visit

\begin{tabular}{lccc}
\hline PLACEBO TIME & $\begin{array}{c}\text { months before } \\
\text { the visit }\end{array}$ & $\begin{array}{c}6 \text { months after the } \\
\text { visit }\end{array}$ & $\begin{array}{c}12 \text { months after } \\
\text { the visit }\end{array}$ \\
\hline & $\begin{array}{c}\text { Weighted } \\
\text { Normalized } \\
\text { Performance }\end{array}$ & $\begin{array}{c}\text { Weighted } \\
\text { Normalized } \\
\text { Performance }\end{array}$ & $\begin{array}{c}\text { Weighted } \\
\text { Normalized } \\
\text { Performance }\end{array}$ \\
\hline & & & \\
VARIABLES & $-0.967^{* * *}$ & $-2.010^{* * *}$ & $0.963^{* * *}$ \\
& $(0.292)$ & $(0.165)$ & $(0.102)$ \\
5-day Pre-visit Window & $0.726^{*}$ & $0.598^{*}$ & 0.212 \\
& $(0.413)$ & $(0.308)$ & $(0.185)$ \\
Day of the Visit & -0.559 & 0.171 & 0.113 \\
& $(0.599)$ & $(0.406)$ & $(0.320)$ \\
5-day Post-visit Window & 0.331 & 0.429 & 0.019 \\
& $(0.350)$ & $(0.343)$ & $(0.184)$ \\
Days 6 to 10 Post-visit & 0.665 & 0.488 & 0.079 \\
& $(0.431)$ & $(0.296)$ & $(0.194)$ \\
Days 11 to 30 Post-visit & $0.510^{*}$ & -0.0867 & $0.422^{* * *}$ \\
& $(0.303)$ & $(0.247)$ & $(0.114)$ \\
Monthly linear time trend & $-0.576^{* * *}$ & $-0.434^{* * *}$ & $-0.287^{* * *}$ \\
& $(0.049)$ & $(0.030)$ & $(0.022)$ \\
Fixed Effects: & & & Yes \\
Service Center & Yes & Yes & Yes \\
Week of the Month & Yes & Yes & Yes \\
Day of the Week & Yes & Yes & 19,671 \\
Observations & 19,355 & 19,671 & 0.553 \\
R-squared & 0.619 & 0.557 & \\
\hline
\end{tabular}

Notes: This table reports OLS regressions of the branch daily sales performance during the year of the placebo RCT. The placebo periods are defined in event time where the event occurs 6 months prior, 6 months after, and 12 months after the day of the actual visit of the division manager to the branch. The dependent variable, Weighted Normalized Performance, is the sum of the individual product daily sales performed by a branch normalized by the population mean and standard deviation for each product and then multiplied by the number of goals scored if the branch meets the monthly sales target for that product; Tournament is a dummy variable that takes the value of 1 if the event time of the observation relative to the placebo visit coincides with the event time of the sales tournament relative to the actual visit and 0 otherwise; Day of the Visit, 5-day Pre-visit Window, 5(10)(30)-day Post-visit Window, and Days 6(11) to 10(30) Post-visit are dummy variables that take the value of 1 if the observation occurs the day of, or in the periods defined as a function of the day of the placebo visit of the division manager to the branch and 0 otherwise.

Clustered standard errors (by branch) in parentheses

$* * * \mathrm{p}<0.01, * * \mathrm{p}<0.05, * \mathrm{p}<0.1$ 